\title{
SHARED KNOWLEDGE AND PRESENTATION OF THE RESEARCH RESULTS IN SPECIALISED SCIENTIFIC PUBLICATIONS
}

\author{
Venelin Terziev \\ Full Member of the Russian Academy of Natural History, Professor, Eng., D.Sc. (National \\ Security), D.Sc. (Economics), D.Sc. (Social Activities), Ph.D. Georgi Rakovski Military Academy, \\ Sofia, Bulgaria; Kaneff University Hospital, Rousse, Bulgaria, vkterziev@gmail.com
}

\begin{abstract}
Many and of different character documents define the relationships and roles in education and science from laws and legal acts, to regulations, standards, simple rules and many others. Every such document plays a certain role in terms of their meaning and content. Within a certain framework, the development of every participant - a teacher, a mentor, a scientist, etc - is related to these systems. All these are a necessary, yet insufficient condition to be a good teacher, lecturer, and scientist. A teacher, a lecturer, a scientist teach, transfer and share knowledge. And knowledge itself is a special category.

How knowledge and research results can reach their users and is passing through specialized scientific publications the only way to it. This research paper considers the possibilities to stimulate scientific publications in Bulgaria and their role.
\end{abstract}

Keywords: research results, scientific research, sharing knowledge, scientific publications.

\section{INTRODUCTION}

In the Oxford English Dictionary knowledge is defined as: facts, information and skills acquired through experience or education, theoretical or practical understanding of the subject, or what is known in a field as a whole, or knowledge, acquaintance gained through experiencing a fact or situation.

Knowing means both a lot and a little. You know a lot, but closed in personal space knowledge remains only individual possession and brings relatively little benefit to others and society. The power of knowledge lies in its sharing - spoken, spread, taught or written. The more space knowledge occupies, the more useful it is for society and its development, it becomes life. Shared knowledge is at the basis of human survival and development. Shared knowledge gives birth to new ideas, creates opportunities and prospects, removes set boundaries, creates new products, opens the door to all developments. In the business environment shared knowledge is an invaluable resource and the engine for the functioning of market relations, from which the end user always benefits.

It is no coincidence that open educational, scientific spaces are being created, which are even part of 
political and social initiatives (Single European Education Area, Single European Research Area, etc.).

In order to share knowledge, you have to master it, you have to not only have somebody else's knowledge that you have realized, given meaning to, thought about, but you have to add an opinion, comment, or your own knowledge achieved through your own efforts. Knowledge is shared in many ways, even often unmarked as such. Teaching and research work are defined as essential in sharing knowledge.

\section{SHARED KNOWLEDGE AND PRESENTATION OF THE RESEARCH RESULTS IN SPECIALISED SCIENTIFIC PUBLICATIONS}

Teaching, disseminating and sharing knowledge with others requires many other things (skills, experience, competencies, mastery of communication channels, various amplifiers, etc.) that cannot be read or found in laws and regulations. What is needed beyond the documents is a certain and high-quality creative energy, dedication, not sparing oneself, understanding, empathy, co-experiencing, unquenchable thirst for knowledge, indomitable spirit, desire for discovery, tirelessness, constant pursuit of excellence, irreconcilability and many other purely professional (professiographic) characteristics. To be a good teacher you don't need to read the pages of the textbook from the teacher's desk, ask the right questions to assess the student, spend the normative classes in the classroom and laboratory and write a number of publications to follow the path of academic growth. Being a good teacher and scientist is a mission that few people bear. And it's not by accident when I say that being a good teacher means being able to share knowledge so that it reaches a lot and reaches them in a way that will provoke new knowledge. It is then that living for knowledge and with knowledge makes sense and is of significance. For those who share knowledge this is the essence and meaning, it is their credo. Is everyone capable of this? To dedicate yourself to the point of exhaustion or not be able to do it. And even if you do not have this opportunity, for a number of reasons, it is a matter of substantive development.

But it is not only through teaching that knowledge is shared. Knowledge sharing takes place in many ways outside of school and university. And these methods are of no less importance, because they create an environment and network for the continuity of the process. This was worked out a long time ago and we apply these methods without thinking about the significance they bring, the effects they create, the influence they define. Conferences, seminars, congresses are the places where knowledge is shared. One and the same knowledge can and should be shared at many different forums. And there is nothing wrong or unnatural about that. One and the same knowledge can be described in many scientific journals, and not only scientific ones, and there is nothing wrong with that either. Thus, it reaches a much larger and more diverse audience, finding its users and consumers. Thus, it provokes new ideas and creates new followers.

Does knowledge need followers? One, I hope, rhetorical question that has a clear answer. Yes - in order to be shared knowledge must have its followers. Otherwise, how will certain ideas, thoughts, judgments or theses reach a certain community and how will they become a necessity for using them. And this is a contribution that not everyone can and does make. It is very fashionable nowadays to talk about "influencers". There is no greater "influencer" than shared knowledge. As long as we give it a chance and do not limit it - to put it in a frame because of a lack of understanding of the meaning or the desire. And even worse - to put it on chains that will keep it only where someone has decided its place is. There have been such times and periods, but today, we hope, they are over.

Today, in the transition from automated to digital systems, knowledge dissemination takes place in ways, methods and techniques different from the ones a century ago. Naturally, the most important of them is learning - formal, non-formal, informal, taking place in and out of school. Moreover, school is supported by many additional methods of knowledge dissemination - organized or unorganized, individual or in groups. Many professors, scientists, researchers, managers and various specialists reason this topic and there is always something different and interesting in their opinions regarding the different types of knowledge and the different ways of their spreading.

At the same time, many administrators not only reason, but also create rules by which knowledge is disseminated and shared, and when everything is put within a certain framework it fades and brings relatively little added value. When administrators create the framework "you can - you cannot", "you get - you do not" and this framework is formalized to the degree of favouritism or elimination, to the degree of creating friendly circles, to the degree of creating an academic stratum without much contribution to knowledge, but with opportunities for distribution of influence - then knowledge loses its main purpose, it loses an awful lot. It loses because the administrator "makes" a bonus from everyone below him in the hierarchy to make them "visible". It doesn't matter which number you are on the list of authors, it's the number that is important. 
Prof. Oleg Georgiev shares his opinion in his recently published article "On the Future of the Academic Tradition" in the "Culture" information portal, namely: "That is why the process of introducing common European quality standards became especially relevant after Bulgaria's accession to the European Union in 2007. Moreover, a leading state-level institution for their introduction through legislative reforms became the National Agency for Evaluation and Accreditation, officially established in the late 90s of the twentieth century, whose mission is to help ensure and improve the quality of higher education. Unfortunately, its activity today has degenerated into a trend fuelled by party experience for power "regulation" of autonomy, imposed by financial, legal and regulatory levers. A blow to the idea of quality was the abolition of the High Attestation Commission, which instead of being reformed was closed and thus was programmed the chaos in the selection of candidates for academic lecturing and research degrees, without anyone seeking responsibility from the then Minister Ignatov; on the contrary, most lecturers were pleased with this chaos and took advantage of it.

The culmination of the desire to control lecturers and under the plausible pretext to raise Bulgarian science to world level was the creation, despite protests, of the National Centre for Information and Documentation, an organization that administratively rendered meaningless the right of universities to care for academic growth of the staff by introducing a system of quantitative criteria and points and thus depersonalizing them and neglecting to the extreme their traditional role. We should not leave aside the fact that this institution follows a strategy that is beneficial to the natural sciences and does not take into account the specifics of lecturing in the sphere of the humanities. Moreover, the measure for scientific criteria that this organization approved are precisely the citations in the scientometric databases Scopus and web of Science, which, however, are suitable especially for the so-called STEM (Science, Technology Engineering, and Mathematics) specialties. This reinforces the feeling that the humanities, and especially philosophy, are now officially seen as unnecessary and second-hand ones. By the way, the damage caused by the forcibly imposed for years "Marxist-Leninist philosophy" as a "methodology of all sciences" led to a reluctance to include the disciplines of the philosophical cycle in the educational process of the Bulgarian academic environment. All this is happening against the background of the total lack of project funding for the humanities on a competitive basis, which are not in the national priorities and are occasionally included in the programs of the National Research Fund.

Today it is a fact that in this situation the universities are forced to fight for their survival and one of their main tasks - doing science, is the work and fruit of the individual efforts of lecturers. The more so that not enough funds are being allocated for this activity, but it is imposed as a requirement and is crucial for the career growth of anyone who is to be scored for it by the National Centre for Information and Documentation.

The most tragic thing here is that the issue of quality continues to be treated administratively and bureaucratically, despite the formal attempt in 2016 to introduce European quality standards in the accreditation methodology of the National Agency for Evaluation and Accreditation. The result - Bulgarian universities occupy unenviable places in the world rankings of universities." (Georgiev, 2022).

True knowledge does not give credit to this model. It tries to come to the surface in another way - informally, personally, with its own handwriting. It puts on its own shoes, enters new auditoriums, appears in front of new audiences and fulfils the mission of sharing and dissemination. Whether this type of knowledge will receive a title or recognition is a matter of approach. Maybe, but not very sure! Is this type of knowledge useful? Yes, because it creates. Isn't participation in various competitions, through which we strive to attract young people to teaching or science, sharing of knowledge? Why do we do it? Because today we are in deficit of leadership in knowledge. Young people are attracted by authorities, not by administrators. Authorities share not to please, but to create followers of knowledge. They are innovators, they are different. They are liked if they are attractive, if they know a lot, if they know how to communicate, if they carry the charisma of the knowledge they have. And isn't this a new reading?

Knowledge which is disseminated through various forms - such as books, magazines (of various kinds), newspapers, electronic platforms and the Internet, means acquaintance with certain content, information on facts of various kinds and allows for understanding, associativity, reasoning, perception, discovery. Certain and different processes start from knowledge. Of course, all these considerations do not provoke a violation of the rules, but seek the change that will create new models of knowledge sharing. Knowledge management and artificial intelligence are part of this unexpected but unavoidable process.

Any method used to disseminate knowledge can be called knowledge sharing. And in my opinion, it is the sharing of knowledge that makes it alive, active, useful, working, effective, ensuring the development not only of the relevant factual resource, but also building a new one. Every teaching activity, no matter where at school, university, training centre, scientific structure - is an activity of dissemination and sharing of 
knowledge. But not everyone who does it gets to the top of sharing. Knowledge sharing is a network activity, with the network growing to enormous proportions requiring strict systematization and consolidation by topic in order to be able to cover and continue to develop. On the one hand, teachers and scientists teach knowledge gained so far, on the other hand, by expressing their own opinion or adding their own research and studies, they enrich and further develop it. With a small amount of knowledge, as was the situation at the beginning of its accumulation, each newly discovered knowledge usually bore the name of the one who added it. This is how there emerged many laws of science that bear the names of their discoverers. This is how the "Eureka" cry has reached many people, but is such a cry achievable today with a publication that will be read by a limited number of people (and in some cases only by the authors)? With the accumulation of vast knowledge bases, which are even difficult to systematize, this does not always happen, or only happens in special cases of serious discoveries and contributions. Recognition of the contribution of anyone who has added even a little new knowledge is done in a different way. Thus, the citation of the contribution becomes an important element of the evaluation of the contribution to the development of knowledge.

Today, when knowledge and science occupy a huge space in economic, social, research life and social development in general, it is becoming increasingly difficult to track contributions. Evaluating contributions to the development of knowledge before you, before your own work, is not so important for documentation as it is important in terms of acknowledgement, ethics in relation to everyone who has given part of their own development to the of development knowledge. Therefore, evaluation of the contribution is inextricably linked to the sharing of knowledge. The difference between evaluation and sharing is that you evaluate and transmit the evaluated knowledge as the original, while in sharing you invest your own understanding or create "new developed knowledge". "I believe that each of us has useful knowledge that can be shared with others and should do so at every opportunity to help others who have taken the same professional path - just as he has received help and guidance from his more experienced colleagues in the beginning. My experience shows that the best programmers, designers, business owners, coaches, etc. like answering questions and helping people who are just starting their careers, changing careers or need other types of help. However, they are rarely asked because many people think that these experts are "unreachable" and are afraid to just write to them and ask their question", said Silvina Furnadzhieva, the site's founder (2022b).

Shared knowledge becomes part of every creative path, i.e. you can share with different audiences, you do it in a different way, adequate to those audiences, and that's part of your participation in the process. And here every way is important, every way is valuable.

We share knowledge orally and in writing. In oral sharing we can omit names, dates, positions, but it is not the same with written sharing. Every name and year is important there. In order to observe not only the ethical norms of the recognition of achievements, but also to give that systematization, which is important from a factual point of view. Also important there is any opinion of the author that has not been "taken" from someone, i.e., the knowledge created by the authors themselves, which become part of the general. And here we come across the terms "citation", "self-citation", "plagiarism", "auto plagiarism" - frightening terms that can not only confuse knowledge sharing, but can also confuse one's destiny. The first two terms are, of course, surmountable and in some cases "over-used" - whether out of reinsurance or out of a desire to create prestige in terms of analytics. When it comes to using the methods of publishing, this can also be expressed by sharing your previous experience (research) and in fact each subsequent work is an upgrade of the previous one. Such sharing can be done and is being done not just once, and it does not in any way violate the norms of knowledge dissemination. And that's important, because that's not just sharing. This is upgrading and becomes part of the overall development of knowledge. In today's science, this is called selfcitation.

According to the Annual Report of the Bulgarian Ministry of Education and Science in 2020, there is stability of the research results obtained at the major research centres in the country in 2020 - the Bulgarian Academy of Sciences, Sofia University "St. Kliment Ohridski" and the Medical University - Sofia. They should be joined by the Technical University - Sofia in the field of engineering, the Agricultural Academy in the field of agricultural sciences and the Medical University - Plovdiv in the field of medical sciences. This practically concentrates almost the entire scientific potential of the country in the capital and the largest Bulgarian city of Plovdiv. This trend is not only maintained, but also deepens the concentration of a high percentage of implemented research projects in the capital's universities and the Bulgarian Academy of Sciences.

Another finding in this report is related to the fact that the reproduction of scientific potential is not enough to compensate for age-related staff decrease in the science research system and is extremely insufficient to provide the Bulgarian industry with doctoral staff. The reproduction of scientific potential in the military schools and the academy of the Ministry of Interior are also insufficient. 
The most unfavourable are the trends observed in comparison with other EU-member countries and the other countries in Europe.

According to the report, there is some lagging in some of the basic indicators for science research activities compared to other EU countries. In terms of number of researchers as a percentage of the total active population against similar characteristics of old EU member states, Bulgaria lags behind by 2.63 times fewer researchers than in Denmark, 2.29 times fewer researchers than in Finland, and 1.44 times fewer researchers than in Greece. Regarding the new EU member states of similar characteristics, Bulgaria lags behind Hungary (1.53 times fewer researchers) and is at almost the same level as Croatia (2020).

Compared to Greece, Slovenia and Croatia, which are member states from the Balkans, Bulgaria lags far behind in terms of overall publishing activity. Regarding the referenced documents in the international databases, the lagging is more than four times compared to Greece, and the lagging behind Slovenia is significant, too. There is also a double lagging behind Serbia, which is not a member of the EU. In terms of the normalized impact of citations, Bulgaria is again lagging behind Greece, Slovenia and Croatia. In terms of percentage of Q1 publications, Bulgaria lags behind Slovenia and Croatia and is almost at one level with Greece (2020).

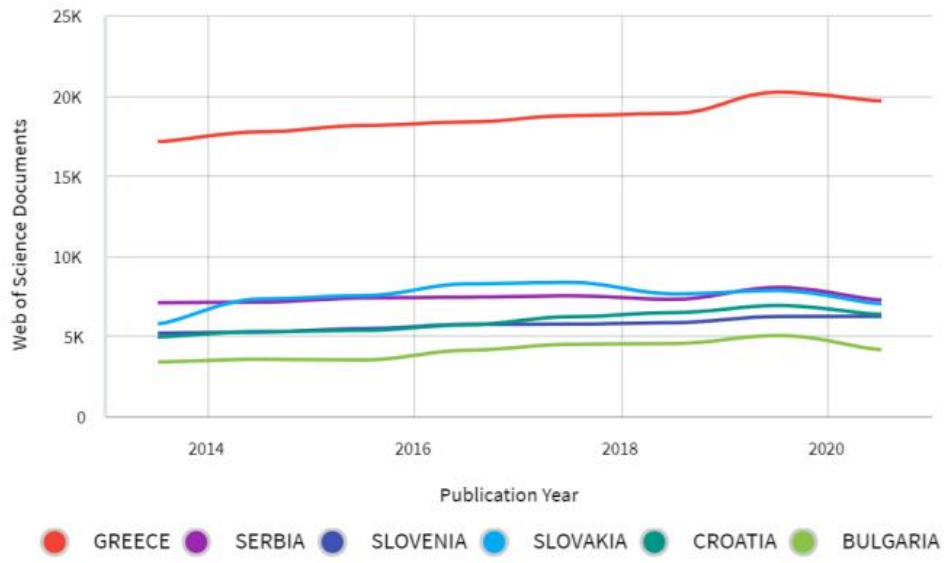

Figure 1. Dynamics of scientific results (number of documents in WoS) for the period 2013-2020 for some comparable-to-Bulgaria EU member states and Serbia (2020)

Indicators: Web of Science Documents. Time Period: 2013-2020. Location: Greece, Serbia, Slovenia, Slovakia, Bulgaria, Croatia. Person ID Type Group: Name. Schema: Web of Science. Location Type: Country/region. Publisher Type: All. Funding Agency Type: All. Person ID Type: Fullname. Person ID Type: Fullname. Dataset: InCites Dataset. InCites dataset updated Sep 30, 2021. Includes Web of Science content indexed through Aug 31, 2021. Export Date: Nov 4, 2021 (2020).

In order to stimulate the publishing activity, as well as the dissemination of the results of science research activity, in October 2021 the Bulgarian government approved the National Program "Stimulation of publishing activity in authoritative international scientific journals and open access to scientific information".

The aim of this program is to stimulate the publishing activity of the research staff and increase the number of scientific publications in reputable scientific journals, referenced or indexed in the global databases Web of Science or Scopus, as well as to promote a culture of open scientific sharing of information and its adoption as a standard practice by the research community.

For funding under the national program can apply higher schools and research organizations with program accreditation for educational and scientific degree "Doctor" by the National Agency for Evaluation and Accreditation and having a profile in the Bulgarian Open Science Portal (BPOS). A necessary condition for participation is that research organizations and universities have and implement internal mechanisms and rules to stimulate the publishing activity of their research teams, as well as open access to scientific information (Terziev, 2021a; Terziev, 2021b).

Researchers will be provided with additional rewards, prizes or other financial incentives for authorship of scientific publications in journals referenced or indexed in the global Web of Science or Scopus databases, bound with sharing of scientific results in BPOS and in institutional or international repositories. 
Exactly how and how much this opportunity will give results to fulfil the set goal is difficult to say at the very beginning of the realization of the program. In some of its components it puts scientific organizations in a certain disadvantage because it is based only on previously proven scientific capacity from the previous year and that in publications that have the relevant $Q$ categories.

It has been established in almost all previous studies of publishing activity that there is a significant imbalance between those from the humanities, social and public sciences and others. This, of course, has its logical explanation, as does the fact that the number of national publications that refer to these systems is relatively small. All this and a number of other reasons put researchers at an unequal position in assessing the achieved and expected future funding. In the current situation, it will turn out that all those scientists and researchers who have successfully published their results in such scientific journals will be funded from the state budget, while others must earn this right over the years. At the very least, differentiation of scientific fields is needed, which will allow for a relatively objective and realistic assessment of the current situation and the expected future results. This has not been done in the current program; rather an assessment under a common mechanism is being carried out. Even the direct relation with the Law for the development of the academic staff and the regulations for its application, which sets specific and different requirements for obtaining scientific degrees and academic positions, sets an objective distinction in different scientific fields and professional fields.

The Ministry of Education and Science in Bulgaria itself makes certain findings of negative trends, such as:

- Many of the publications reported on the Web of Science and InCites, especially in the field of natural and medical sciences in Q1 and Q2, are in fact summaries of scientific events published in Supplement format in indexed journals. Their participation should be reported separately from the full-text publications, with a proportionately reduced contribution;

- There is a serious problem in eliminating auto-citations. The question of how independent it is to cite a publication with more than 30 authors by more than 10 organizations when cited in other publications related to this consortium remains controversial. At individual-author level the problem can be solved by the instrumentality of Scopus, which allows selective exclusion of self-citations of an individual author or group of authors. As regards organizations an adequate solution of the issue is yet to be found. The same goes true for monographic works, too. Contradiction arises when books are cited in general or when specific chapters in them are cited. It is not clear whether if a co-author of a collective monograph participates in the citation publication but a different chapter without his direct participation is cited, this can be considered as an independent citation, and whether citing the monograph as a whole can be considered a citation in benefit of all works included in it.

\section{CONCLUSION}

Even incomplete statistics on the publishing activity of Bulgarian scientists which are part of various government reports, accreditation procedures and other researches, put Bulgaria in a far from enviable position with comparable countries such as Greece and Serbia. Studying the consequences of this condition is very important for making accurate and correct decisions. Creating programs is part of such a more comprehensive and important national strategy, but it will in no way improve the situation we are in.

It is necessary to structure a good mechanism that will encourage science researches and make them a priority for the national economy, and from there to give impetus to the reflection of these researches in international scientific journals.

Overcoming the negative consequences of the restructuring of the systems - political, economic, social, educational, etc. - will require time and concrete efforts in this direction.

\section{REFERENCE LIST}

Georgiev, O. (2022a). About the future of the academic tradition, http://kultura.bg/web/\%d0\%b7\%d0\%b0$\%$ d0\%b1\%d1\%8a\%d0\%b4\%d0\%b5\%d1\%89\%d0\%b5\%d1\%82\%d0\%be-\%d0\%bd\%d0\%b0-

\%d0\%b0\%d0\%ba\%d0\%b0\%d0\%b4\%d0\%b5\%d0\%bc\%d0\%b8\%d1\%87\%d0\%bd\%d0\%b0\%d1\%82\% $\mathrm{d} 0 \% \mathrm{~b} 0-$

$\%$ d $1 \% 82 \%$ d $1 \% 80 \%$ d0\%b0\%d0\%b4\%d0\%b8\%d1\%86\%d0\%b8\%d1\%8f/?fbclid=IwAR1AjMT2PcbWld Kwa3wmr4_qUQK30gCqlbHVtmEoMqhFfRf8Voqe7vyNFMo, 01/2022. 
https://www.edinvapros.org/, (2022b), 01/2022

Report from the permanent expert commission for monitoring and evaluation of the research activity carried out in the higher schools and the scientific organizations for 2020, (2020).

Terziev, V. (2021a). Shared knowledge as a part of open science. // 21st RSEP International Economics, Finance \& Business Conference - Virtual/Online 19-20 May 2021, HCC. St. Moritz Hotel, Barcelona, Spain, RSEP, Ankara/Turkey, 2021, pp. 126-131, ISBN: 978-605-70583-0-0/May 2021.

Terziev, V. (2021b). The open science as part of knowledge sharing. // XXXI International Scientific Conference: The Teacher of the Future, June 23 - 26, 2021, Budva, Montenegro, Knowledge International Journal Vol. 43.1, Institute of Knowledge Management, Skopje, N. Macedonia, 46, 2021, 1, pp. 83-90, ISSN 1857-923X (for e-version), ISSN 2545 - 4439 (for printed version). 